involves splitting the concrete into fragments (psychological, economic, administrative, etc.).

3. Work in the two realms involves different organizational frameworks. Political work, for instance, is typically done in large, routinized organizations. Academic inquiry, although becoming more bureaucratized, still is mostly done individually, with few prescribed routines.

4. Time and space involve different dimensions in the two cultures. Political space is tied, in the main, to particular societies; scientific space is ecumenical. Political time is inherently short; action usually must be expeditious, whether or not all the returns are in. The academic may sit long and patiently (even now, despite the overemphasis on rapid "productivity"), thinking, calculating, or awaiting inspiration.

All this, to repeat, is only a summary of a rather elaborate argument and rationale. It should suffice to help explain why the two roles, ideally complementary precisely because of their differences, often only lead to misunderstanding, even contempt, in interaction. It should also help explain why the practical men largely seek out their own kind in the academy, and vice versa, when the opposite would be much more useful.

As for the dangers: Weber pointed out that the chief peril of confusing the two life-worlds to social scientists is the temptation to play at being moral teachers, agitators, demagogues, and "prophets" in the academy-something that can, of course, also occur through dissident "engagement." This is a danger, granted, only if one agreed with Weber on the limits of science (its inability to provide "correct" values and to infuse "meaning" into life, and its inability to yield final, definitive Truth) and with his perception of its peculiar dignity as an activity, which lies precisely in the taxing labors scientists perform despite these limits.

In the case of politicians the chief peril is what Weber called "scientism." That meant two things to him. One is turning a scientific theory into a moral imperative, which compromises both theory and morality. The second involves "politicians" more directly. The need for choice often is pressing in the "real world" and choices often are difficult to make. If so, the practical men may thus become only too susceptible to the scientists, abdicating to them the responsibilities intrinsic to their roles. Actually, both types of men may thus become unfaithful to their responsibilities if their roles are confused: in one case, to inquire; in the other, to choose.

There is more to be said about all this-much more. Suffice it to say here that, though exhortations to do "applied political science" may be salutary as an antidote to too strict separation, we need much more the careful, subtle analysis of desirable linkages of, and division between, the roles, in the manner of Weber's lectures-splendid lectures, but certainly not the last words on the subject.

\section{References}

Braybrooke, David and Charles E. Lindblom. 1963. A Strategy of Decision: Policy Evaluation as a Social Process. New York: Free Press.

Eckstein, Harry. 1967. "Political Science and Public Policy." In Ithiel de Sola Pool, ed., Contemporary Political Science. New York: McGraw-Hill.

Lindblom, Charles E. and David K. Cohen. 1979. Usable Knowledge: Social Science and Social Problem Solving. New Haven: Yale University Press.

Weber, Max. 1946. From Max Weber: Essays in Sociology. H. H. Gerth and C. Wright Mills, transl. and eds. New York: Oxford.

\title{
Whither the Political Science Major at Liberal Arts Colleges?
}

\author{
Timothy V. Kaufman-Osborn, Whitman College
}

Note: The following remarks were delivered at a roundtable conducted under the auspices of the American Political Science Association at its 1989 annual meeting in Atlanta. The session was titled "Re-thinking the Political Science Major at Liberal Arts Colleges." Other participants included Joan Tronto, Hunter College; Raymond Seidelman, Sarah Lawrence College; and Timothy Cook, Williams College. The views expressed here are my own and do not necessarily reflect those of my colleagues in the Department of Politics at Whitman College.

The liberal arts college at which I teach is distinguished chiefly by the obscurity of its location in Walla Walla, Washington. Assuming my position at Whitman College in 1982, I inherited a conventional political science major. Courses were divided into four subfields: American politics, political theory, international relations, and comparative politics. Students who elected to complete this major were required to enroll in at least one introductory course in each of these areas; and, as seniors, all were subjected to written examinations on three of the four as well as a more comprehensive oral examination.

At the time, this program seemed familiar and unobjectionable. On the whole, its form recapitulated that of the graduate program I had just completed as well as that of the APSA Personnel Newsletter. As the years passed, however, concerns about the adequacy of this structure became ever more pressing. My first intimation that something was amiss emerged when, as chair of the department, I found it necessary to determine the appropriate subfield designation for new courses titled "Politics and Literature" and "Politics and Film." These administrative inconveniences blossomed into outright anomalies when, in response to personnel changes, our courses in law came to be taught primarily by a political theorist rather than by an Americanist. Did this mean that this area was now to be accorded a new subfield location? Moreover, what was I to do with courses, like those in political economy, which seemed to escape altogether the tidy confines of our 
major? Faced with the choice of either proliferating subfields or turning our program's structure into a Procrustean bed, my colleagues began to ask broader questions about the appropriate form of the political science major at a liberal arts college.

To perceive the truth and to will its demands are often two quite distinct matters. Loathe to scrap the wisdom of the past without first securing some guidance, we turned to a study of political science majors at comparable institutions. To our dismay, virtually without exception, we could find no program that diverged significantly from that which we already had. Still hoping to delay the inevitable, I began an inquiry into the evolution of our current program; and that, in turn, led to a more comprehensive investigation into the original emergence at Whitman College of an autonomous department dedicated to the study of matters political. Together, these explorations persuaded me that the internal perplexities faced by our department reflected a dilemma that now afflicts the liberal arts college as a whole.

Acknowledging the danger of generalizing on the basis of a single institution's experience, I wish to express my tentative conclusion in the form of two interrelated contentions. First, I want to suggest that the structure of the political science major at institutions like Whitman is best read as a manifestation of the university's success in reducing the liberal arts college to the status of a colonial dependent. Second, I want to argue that this conquest cannot itself be understood apart from the changing cultural status of science in the United States around the turn of the twentieth century.

Much American higher education during the latter half of the nineteenth century took place in small colleges rather than universities. More often than not, these colleges were founded by persons hoping to institutionalize and advance a particular body of theological doctrine. Not surprisingly, therefore, the transmission of knowledge was intended to improve its recipients not by expanding their grasp of valueneutral facts, but rather by improving their character-more specifical-

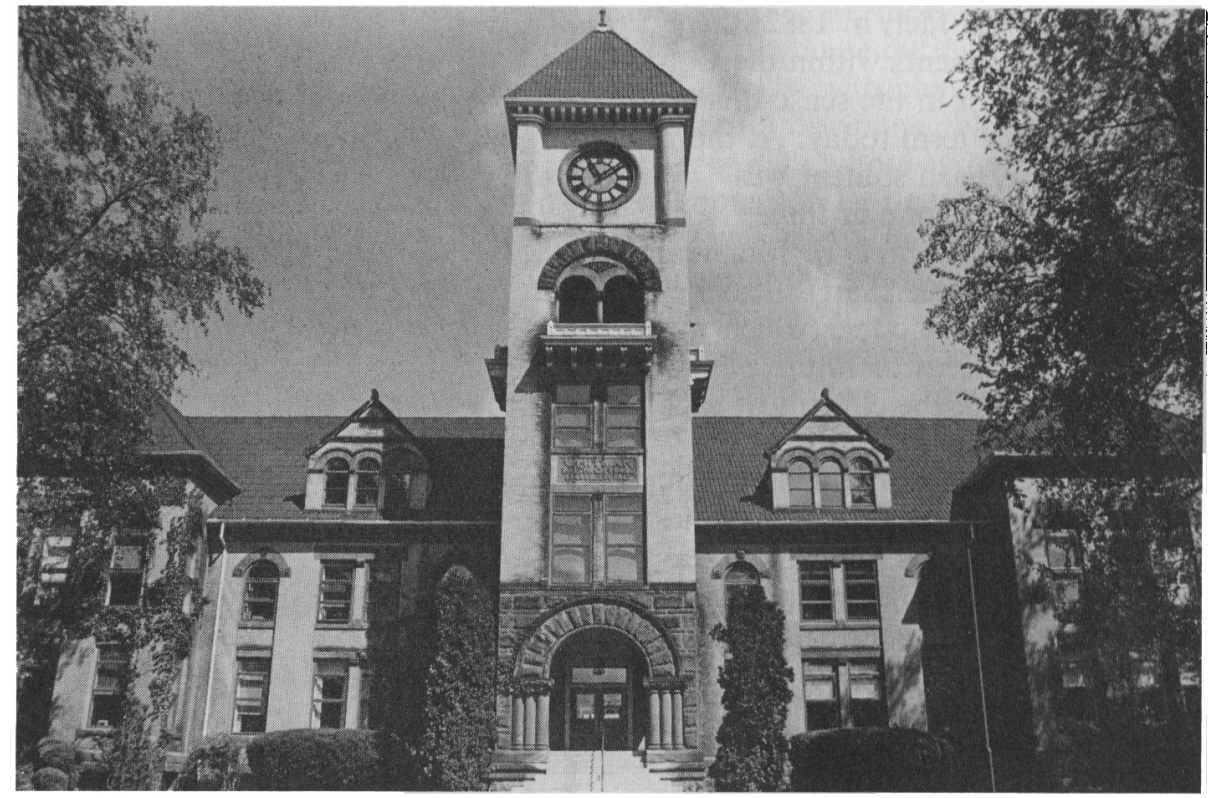

Whitman Memorial Building, Whitman College.

ly, by instilling Christian virtue through the medium of wisdom. Consequently, to the extent that what we now call "natural science" was taught, it was understood as a field of study integrally related and ultimately subordinate to theological truth.

By and large, America's liberal arts colleges during this period offered a fairly standard course of instruction. Its content emphasized the study of Greek, Latin, some mathematics, "natural philosophy," history, and a considerable dose of moral philosophy. The inclusion of these subjects as opposed to others was often justified, explicitly or implicitly, through reference to God's providential plan for humanity. Each of these finite fields of knowledge was thought to have an assigned place and defined purpose within a larger whole which, as a complex but harmonious unity, contributed to the greater glory of God. This idea was perhaps best expressed in John Newman's The Idea of a University, originally published in 1852. In that work, Newman took the Aristotelian premise regarding the unity of all knowledge, and relocated it within an essentially Thomistic understanding of Christian theology. So synthesized, this mix effectively dictated the form and content of an education in the liberal as opposed to the "ignoble" vocational arts; and the individuals who taught these arts, often bearing titles like "Professor of Moral and Mental Philosophy, Political Economy, and Polite Literature," stood as living embodiments of the liberal ideal.

Whitman College during the late nineteenth century fit this model reasonably well. The 1882 catalogue opens by noting that the "College is situated at Walla Walla, Washington Territory, the metropolis [sic] of eastern Oregon and Washington and northern Idaho"; that tuition is $\$ 16.00$ a term; and that there are five students as well as five faculty members presently in residence. It then assures the wary reader that the College, although "not under the control of any presbytery, synod, association, conference, or other ecclesiastical body, or of bishop or State," is nonetheless governed by a Board of Trustees, "bound by an irrepealable article of its constitution to maintain, in conducting the Institution, evangelical principles of Christianity." In the same vein, it goes on to express the hope that this "College, the only institution of higher learning of the New England type proposed for this vast region," will "have a rapid growth, and speedily become a strong power towards building up with the growth of this new land a civilization based upon thorough scholarship and Christian principle."

In turning to curricular matters, the catalogue makes no mention of a department bearing the name "polit- 
ical science." In fact, in 1882, there were no departments within the College, at least not in the sense that we understand the term today. At the time of entry, each student was required to select one of three "courses," i.e., a three- or four-year course of study (see chart). Leaving aside the Normal Course (which was geared to the needs of future public school teachers), the content of each was delineated as follows: "The Classical course covers the usual four years of classical study, mathematics, science, English language and literature, history, civics, economics and philosophy. The Scientific is a threeyear course intended for those who have not the time to take the classical. It is the same as the classical with the omission of Greek, a part of the Latin, and a few other branches. The Literary is the same as the scientific, except that candidates may, with the consent of the Faculty, substitute Latin, French or German for the higher mathematical studies of the course." (The Literary course was designed for women who, in virtue of their delicate nature, were not adequately equipped for the rigors of advanced mathematics.) In any event, note that there was substantial overlap between each of these "courses." All students taking the "Classical" course studied Geometry, Algebra, Botany; all students taking the "Scientific" course studied Virgil, Caesar, and Cicero; and so forth and so on. Consequently, the dangers associated with excessive specialization simply did not arise. Moreover, note that in the senior year every student, regardless of the course he or she originally selected, was required to take "Evidences of Religion," "Ethics," and "Constitution of the United States." Thus, when politics was studied, it was not set apart as an independent domain of expertise. Rather, along with Christianity and the moral code derivative upon it, politics stood at the apex of the larger synthetic curriculum from which it derived its meaning and purpose.

What accounts for the disintegration of this vision of higher education, and how is that deterioration reflected in the organization of Whitman College's curriculum? In answering the first question, one may

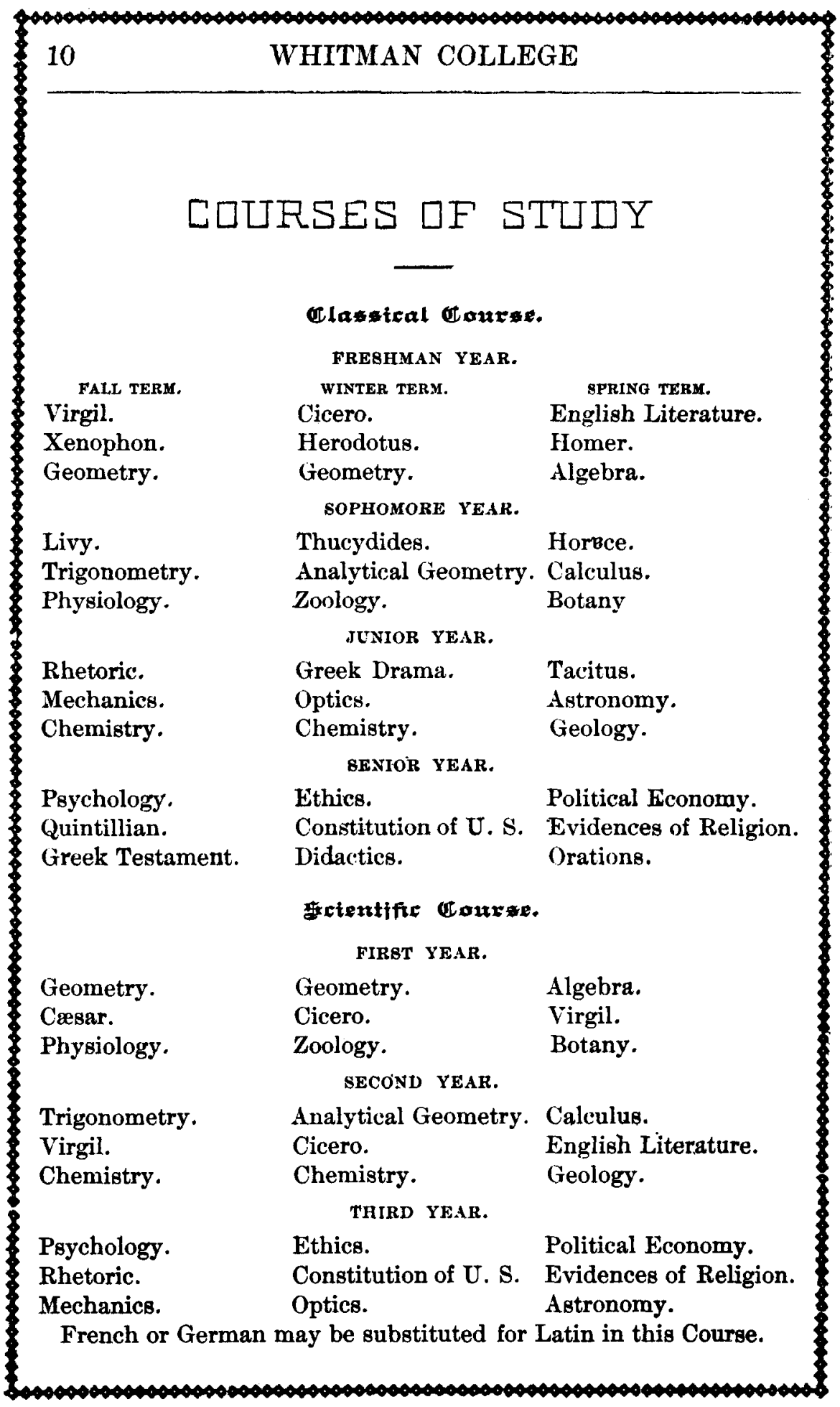

Whitman College course of study, 1882-83. Whitman College.

point to any number of causes. Clearly, though, one of the most important is the growth of the modern university system which cannot itself be understood apart from transformations in the status of science within American culture. What one sees in the closing decades of the nineteenth century is the gradual disengagement of "natural philosophy" from theology. As science comes to displace the Bible as the authoritative ground of American educational practice, the idea of transmitting wisdom through teaching rooted in faith wanes. What slowly takes its place is our now familiar idea that knowledge is something to be accumulated by professionals and conveyed by experts whose authority 


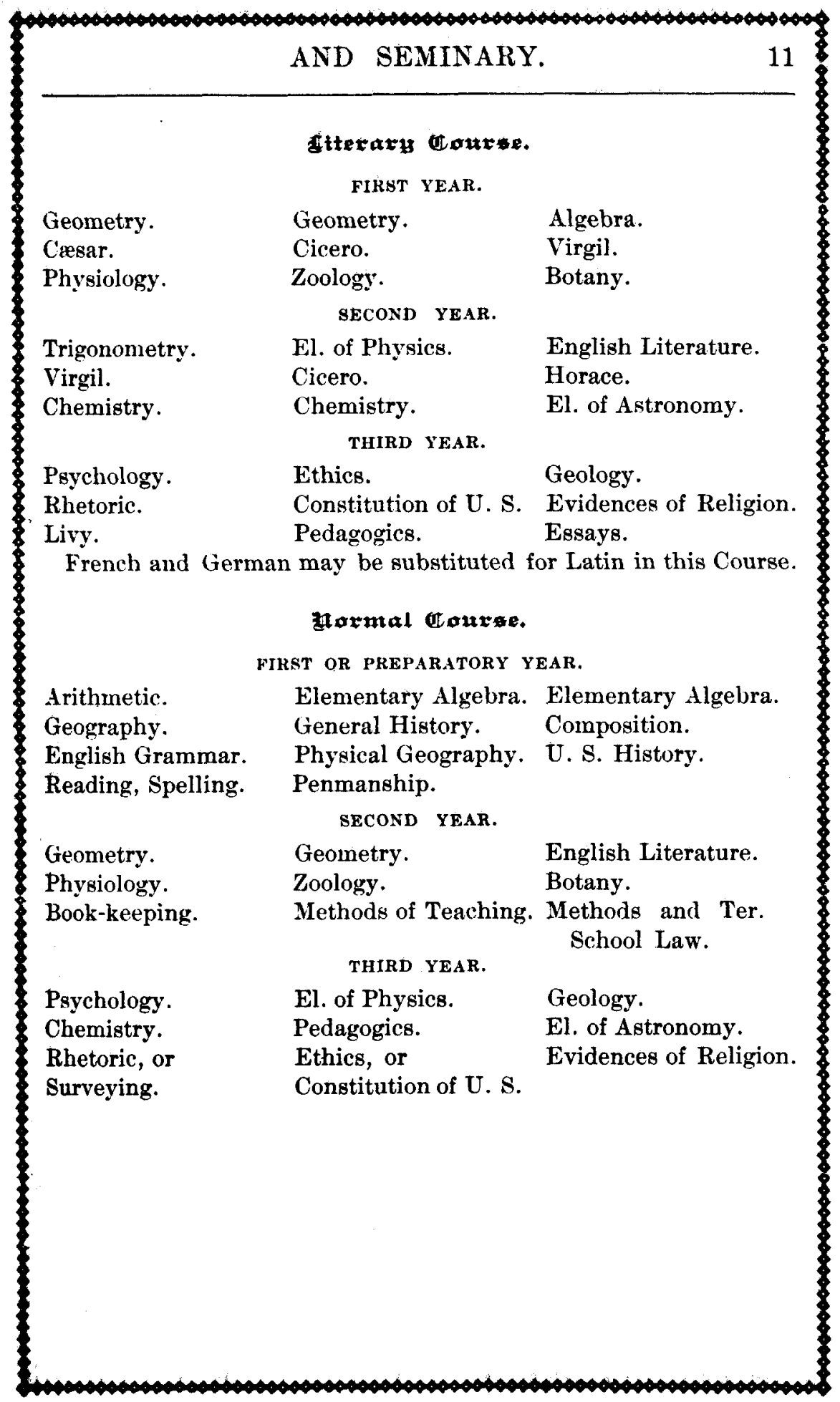

stems from their disciplined mastery of a specialized epistemic province.

As it becomes ever less apparent that all knowledge is coherently integrated within and by God's providential plan, one academic discourse after another disengages itself from the architectonic structure celebrated by Newman. Moreover, and no doubt expressing the awe inspired by modern industry's rapidly-expanding capacity to turn the findings of scientific inquiry into instrumentalities of technological power, the majority of these increasingly autonomous discipines, to a greater or lesser extent, endorse the view that the methods of the natural sciences represent the only route through which knowledge worthy of the name can be gen- erated. In sum, most fields of academic discourse during this period are stricken with physics envy, i.e., envy of a discipline able to generate precise data whose systematic interrelations can be formulated as necessary laws and, when so stated, employed in the exercise of apparently limitless power.

This is an appropriate way to understand the emergence of political science as an independent discipline. Political science acquired departmental status at the University of California in 1903; at the University of Illinois in 1904; at the University of Wisconsin in 1904; at the University of Michigan in 1911; and at the University of Minnesota in 1915. Moreover, like most other newly-emergent social sciences, the founders of political science generally embraced the claim that inquiry into political matters could produce genuine knowledge only by emulating the natural sciences. Granted, what counted as science within the early discipline was not especially sophisticated. For the most part, the appeal to science reduced to a plea to consider the facts without prejudice. Hence James Bryce, the APSA's fourth president, called upon his colleagues to "stick close to the facts" and avoid losing themselves in "abstractions" and "metaphysical concepts" like those suggested by the terms "law" and "state." Charles Merriam, however, made quite clear the larger purpose implicit in Bryce's exhortation when he insisted that methodological inquiry into the facts of political behavior (rather than fidelity to God's law) now offered the sole route to collective salvation: "The whole scheme of governmental activity requires a body of scientific political principles for even reasonable efficiency and success. ... . The need of today is for developing the powercontrolling sciences until they equal the efficiency of the power-creating disciplines, to the end that mankind can become the conscious arbiter of its own destiny. We must evolve a system of social control by which reason rather than passion will be the dominating power."

As many have recognized, the institutionalization of political science as an autonomous area of inquiry is just one sign of a much larger phenomenon. At an ever faster clip, 
early twentieth century America witnessed a partitioning of knowledge amongst so many camps of specialists, each seeking to establish its exclusive rights over the field upon which it had staked its claim. This, of course, explains why more and more disciplines during this era came to insist that only peer review could determine what constitutes reliable truth. And, correlatively, it explains why more and more disciplines found it advisable to organize separate associations devoted to promotion of a professional ethos. By the turn of the century, the American Social Science Association, initially founded in 1865 to insure the integration of all knowledge regarding specifically human subjects, could no longer resist the centrifugal forces generated by this dynamic. In 1884 , the American Historical Association broke away from the ASSA; the American Economic Association in 1885; the American Psychological Association in 1892; the American Anthropological Association in 1902; the American Political Science Association in 1903; and, finally, in 1905 the dessicated remains of this once impressive association were officially reconstituted as the American Sociological Association.

These transformations in the business of knowledge did not leave traditional liberal arts colleges unchanged. Then, as now, most postsecondary school teachers received their Ph.D.'s from the large universities in which independent disciplines were so quickly proliferating; and so, not surprisingly, liberal arts colleges ever more looked to this quite different sort of institution for cues regarding the appropriate form and content of knowledge. As a result, the structure of major programs at such colleges gradually came to incorporate and express the ethos of those trained to think of themselves as specialists devoted to the accumulation of knowledge in defined areas of expertise.

To see how these global processes took shape closer to home, or at least my home, let me return to the example of Whitman College. In 1892, an ominous paragraph appeared in the College's catalogue. That paragraph, bearing curiously contemporary resonances, reads as follows:

Whitman College during the past year has been completely reorganized, and plans are under way to develop it into an ideal American College as rapidly as its resources will permit. . . . The three College courses are now made of equal length, and, as nearly as possible, of equal difficulty. This, too, is in accordance with the usage now prevalent in all good colleges. Of necessity they correspond more closely than is desirable. But to have a greater range of scientific and literary studies is impossible till we are provided with a larger faculty. As the college secures endowment, and the various departments are properly separated, and in charge of specialists a wider range of optional and elective studies will be introduced.

Two years later, in the $1894-95$ catalogue, individual departments are first carved out. These include the Departments of Philosophy, Greek, Latin, Math, Natural Sciences, Modern Languages, and finally, that of History, Civics and Economics. In this year, however, individual departments are still subordinate in function and status to the three courses I mentioned above, i.e., the Literary, the Classical, and the Scientific. They supply an additional level of administrative hierarchy, but do not replace the nineteenth century's classical curriculum.

This order stays essentially unchanged for the next decade or so, although several new departments, including those of Physics and Chemistry, are invented. But in 1904 there is a fundamental shift, as the curriculum's division into courses of study is rejected in favor of a system of independent majors. Under this new regime, by the end of his or her first year, each freshman must commit a substantial block of time to a chosen department in addition to completing what is called "prescribed work." Political science, though, is not an option since it has yet to spawn a department of its own. Curiously, however, in one instance and one instance only, there is no one to one correspondence between possible majors and existing departments. For while there is a Department of History and Economics (Civics has already dropped by the wayside), students interested in such matters must major in something called "Philosophy, History, and Political Science." Reflecting a more traditional notion of knowledge, these three disciplines remain wrapped up within a single area, and so resist the specializing impulses now so pronounced in most other fields of inquiry.

In the following year (1905), a W. D. Lyman establishes separate departments devoted to the study of history and economics (even though there is only a single faculty member in each, and he is it). Most of the courses offered in these two departments have as their prefix the term "political" (e.g., "Political Economy," "American Political History," etc.), thus indirectly acknowledging the rightful primacy of politics over its lesser brethren; yet still there is no major exclusively dedicated to its concerns. One year later, it becomes possible to pursue a major in any one of the three departments of Philosophy, History, or Economics; and, in 1909, the latter changes its name to the Department of Economics and Social Science, thereby enabling it to introduce courses on "The Labor Problem" and "The Trust Problem" without calling attention to political science's status as an administrative orphan. The forces of disciplinary justice finally assert themselves in 1911 as a Department of Political Science is founded, and courses on American Government, Municipal Government, Comparative Government, etc. are added to the already established curriculum. Even more noteworthy, the department's founder succeeds in appropriating the courses formerly taught by the Department of Economics and so consigning the latter to administrative oblivion. (Economics, incidentally, does not regain its autonomy until 1914 when, revealing its true stripes, it is reconstituted as the Department of Economics and Business.) The triumph of modernity is perfected when, in 1914, Whitman becomes the first college in the nation to require every undergraduate to complete a comprehensive examination in a major field of study.

In passing, it is worth noting the essentially bureaucratic response prompted by collapse of the nine- 
teenth century's curricular synthesis. In 1911, Whitman seeks to temper the flux described above by consolidating its various departments within what are called "groups." Group I bears the title "Philosophy, History, and Political Science"; Group II is called "Languages and Literature"; and Group III goes by the name "Mathematics and Science." These associations, obvious forerunners of the now familiar division of the liberal arts curriculum into the social sciences, the natural sciences, and the humanities, are best understood as pale reincarnations of the three "courses" into which the College's curriculum was originally partitioned. Categories once used to offer students a choice of emphasis within a curriculum unified by shared theological presuppositions are now reborn as formalistic containers serving the purposes of administrative convenience. (Incidentally, in 1921, Group I was rechristened "Philosophy and Social Sciences"; not until 1956 was it discovered that philosophy, unable to achieve "hard" scientific status, merited expulsion from Group I and relocation in the "mushier" domain of Group II, which was then renamed "Humanities" so as to accommodate its new member.)

I go through this history to make two basic points. First, at Whitman and I suspect at most other liberal arts colleges, disciplinary categories during the last decade of the 19th and the first two decades of the 20th century were remarkably mutable. The achievement of stability, however temporary, turned not so much on consideration of the best way to divide up the world for the purposes of comprehension, but rather on who had sufficient authority and resources to carve out a separate fiefdom and protect it from conquest by others. Second, at Whitman and elsewhere, the evolution of political science as a separate discipline as well as its subsequent internal decomposition into so many subfields, reflects certain defining trends of modern America. The creation of autonomous academic departments, the emphasis on the undergraduate major, the insistence upon comprehensive examinations to demonstrate competence in specialized areas of inquiry, etc. are symptomatic of (a) the university's displacement of the liberal arts college as the most prestigious locus of higher education; and (b) our collective shift from a worship of God to a worship of science.

If these conclusions are valid, then I think we need to ask whether pedagogical presuppositions taken from large universities are appropriate to the liberal arts college. Do we want the internal organization of majors at such colleges to be dictated by principles and ends that first developed within a very different institutional form? To the extent that familiar sub-field categories are used to label individual teachers, the university model discourages faculty from poaching upon one another's territories and so running the risk that they might learn from one another. Because it does little to encourage students to fashion some more comprehensive vision of political life from their diverse courses, it fails to meet the needs of those who, for the most part, will confront political issues not as experts, but as citizens. And, finally, it encourages us to give way to that most alluring of academic temptations, i.e., that of identifying the administrative categories of our major programs with the structure of political experience itself. In sum, if we wish to rethink the ideal of a liberal arts education, we can take a vital first step by loosening the grip of the university upon our curriculum.

The details of my department's particular efforts to do so are not especially significant. In a nutshell, we have abolished the sub-fields as well as the requirements derivative on them. In their stead, we have moved to a few simple distributional requirements which insure that students take courses of varying levels of difficulty. Consequently, the burden for assuring adequate breadth of coverage has shifted to the less legalistic confines of the advisor/ advisee relationship. We have also required completion of a team-taught departmental senior seminar devoted to discussion of contemporary political issues as well as composition of an integrative essay which, in order to institutionalize the practice of rewriting, is drafted during a student's second to last semester and reworked during the last. Finally, as an expression of these reforms, the department has changed its identifying label from that of political science to that of politics. Although the term "political science"' has a history extending back into the sixteenth century, it was not widely affixed to academic departments until there emerged a discipline more or less united by the conviction that a single method was peculiarly appropriate in investigating things political. The post-war era, however, has made a shambles of that article of faith. Believing that what joins us together is a shared preoccupation with politics rather than a determinate methodology, we have felt obliged to introduce a less exclusive form of collective self-representation.

Were the line of argument suggested by these remarks pursued more rigorously, I would no doubt find it necessary to advance a much more thoroughgoing critique of the practice of American higher education. Granting this deficiency, these comments are offered merely as an invitation to reflect upon the desirable form of a major program that acknowledges the differences between the ends of a large graduate-oriented university and those of a small teaching-oriented liberal arts college.

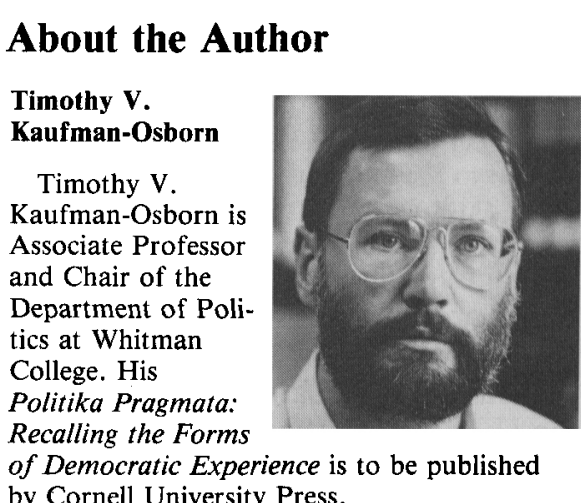

by Cornell University Press. 